\title{
EDGAR ALLAN POE NA FRANÇA E NAS CARTAS DE STÉPHANE MALLARMÉ
}

\author{
Sandra M. Stroparo
}

Plus qu'un seuil, l'épistolaire dessine un arrière-pays de la création littéraire...

(Brigitte Diaz, L'épistolaire ou la pensée nômade)

O epistolário de escritores importantes há muito é fonte de estudos e comentários sem que uma justificativa teórica precise ser apresentada a cada novo texto crítico. A correspondência é, com frequência, não só reveladora de alguns princípios que regeram o trabalho de criação mas do próprio caminho percorrido para alcançá-los. Nesse contexto, pensar a questão da tradução a partir de corpora epistolares é não só factível mas especialmente interessante, considerando-se que a teoria da tradução, como disciplina acadêmica particular, é muito mais recente que a sua prática propriamente dita.

Mas há momentos em que a troca de correspondências esteve de tal forma arraigada à cultura e às práticas sociais de um grupo ou de uma sociedade, que descobri-las possibilita muitas vezes reviver, ainda que vicariamente, processos de descobertas pessoais, nascimento e desenvolvimento de posturas estéticas, escambos livrescos e grandes amizades literárias.

Um desses momentos férteis foi o século XIX francês.

Para que se tenha uma idéia da importância da carta nesse momento, podemos apontar um dado interessante: na França pós-revolucionária, um país mais alfabetizado do que jamais tinha sido, a carta era um elemento de tal forma importante que mesmo manuels épistolaires, manuais epistolares, se transformaram em um grande sucesso editorial. A Bibliothèque Nationale Française guarda, para o período entre 1830 e 1899, o registro de 195 títulos diferentes multiplicados em um total de 616 edições $^{1}$. O que percebemos com isso é na verdade um interesse bastante generalizado e a evidência da presença constante da "mídia" epistolar na vida das pessoas, bem como um interesse específico pelo refinamento dos textos das cartas,

1 DAUPHIN, Cécile. "Les manuels épistolaires au XIX ${ }^{\mathrm{e}}$ siècle." in: CHARTIER, Roger. La correspondance: les usages de la lettre au XIX siècle. Paris: Fayard, 1991. 
visto que os manuais também proporcionavam isso. E sobretudo, é claro, o vigor do mundo editorial francês.

O volume de publicações francesas da segunda metade do século XIX, especialmente se consideramos a relação entre a população leitora e o número de escritores, é de dar inveja a qualquer feira de Frankfurt dos nossos dias. Foi nesse ambiente aquecidíssimo que a Europa produziu um de seus momentos artísticos e culturais mais importantes, num período que começa em torno da década de 70 e vai até o entre-guerras do século XX: grande circulação de pessoas, obras e interesses de toda ordem, com a burguesia criando e sustentando um novo modelo cultural.

\begin{abstract}
Durante os anos de 1880, o número de livros publicados na França aumentou dramaticamente a cada ano, chegando ao ápice em 1889, quando perto de 15 mil títulos apareceram só naquele ano. Uma pequena redução ocorreu na década seguinte, mas o volume ainda era grande, com uma média de 12 mil novos livros de verso. Sublinhando a expansão da publicação de livros estava o crescimento ainda mais rápido de periódicos. Entre 1885 e 1895, uma média de 985 novos jornais literários foram lançados a cada ano, enquanto que em 1860 havia menos de 500 periódicos no total, contando os estabelecidos e as novas empreitadas. Em 1889, o editorial do primeiro número de La plume anotou que 1747 jornais eram publicados apenas em Paris e satirizava que eram 1746 demais. La plume durou 15 anos, mas a maioria dos jornais pequenos sucumbia rapidamente depois de um punhado de números. $\mathrm{O}$ pessoal ia adiante, esperando encontrar a chave do sucesso, mas mesmo diretores de pequenos jornais de sucesso não podiam ganhar a vida a partir desse trabalho. ${ }^{2}$
\end{abstract}

A multiplicação de periódicos, como esses dados mostram, representa na verdade uma espécie de escada para a concretização do livro. Escritores multiplicavam a inserção de textos em periódicos até que alguma aceitação e um número suficiente de poemas ou "trechos" de obras maiores justificasse a publicação de uma obra completa, um primeiro livro que frequentemente já surgia com cara e nome de antologia, "recolha", "encontrados", "reunidos" ou algum outro termo equivalente.

Mas num meio farto como esse, os grupos e as preferências vão se organizando e muitas vezes o que vemos hoje confortavelmente situado na unanimidade do cânone teve um surgimento um pouco mais tumultuado e difícil do que os estudos culturais gostariam de admitir. A própria efemeridade da maioria dos periódicos já é prova da realidade hesitante em que se encontrava a produção da

\footnotetext{
${ }^{2}$ SMITH, Richard C. "Crises of opportunity" in: Mallarmé's children: symbolism and the renewal of experience. Berkeley e Los Angeles: University of California Press, 1999. p. 49. Todas as traduções, exceto quando indicado, são minhas.
} 
época, em um meio vasto mas incerto, em constante variação. Dessa forma, a articulação de grupos intelectuais e o reconhecimento comum de certas referências valia muitas vezes como uma espécie de passaporte com vistos múltiplos, o que, apesar de certas aceitações prévias, não era também garantia absoluta de publicação.

Façamos então um recorte: esse é o ambiente que recebe as traduções de Edgar Alan Poe na França, começando com o interesse de Baudelaire e chegando ao esforço constante de Mallarmé: elas foram aos poucos sendo mostradas a alguns amigos em correspondência, apareceram, em partes, nos periódicos, e foram finalmente publicadas em livros. O que percebemos, entretanto, é que o espaço da correspondência é frequentemente o da apresentação e aceitação inicial, e isso vale para a produção original assim como para os trabalhos de tradução.

Assim, se tomarmos como exemplares essas traduções da obra de Edgar Alan Poe descobrimos um caso paradigmático dos processos que envolveram esse trabalho e como a comunicação entre os implicados deixava entrever as circunstâncias da tradução. É importante não esquecer que, sobretudo no caso escolhido, foram interesses pessoais que determinaram a descoberta do autor estrangeiro e o desejo de traduzi-lo, e não alguma encomenda ou prévio interesse editorial: os tradutores foram os responsáveis pela descoberta e "promoção" da obra do traduzido em língua francesa.

A Baudelaire resguarda-se a primazia e Mallarmé o seguiu, influenciado por ele. Mallarmé, no entanto, foi o principal responsável - Baudelaire não teve esse tempo - por manter o interesse em torno da obra do autor americano, especialmente por ter feito contato com outras pessoas, alguns escritores, igualmente interessados em Poe, e por ter feito o primeiro contato efetivo com o mundo editorial norteamericano. Embora não encontremos comentários de caráter de fato tradutório, algumas observações gerais e todo o trajeto entre o interesse inicial, as traduções e finalmente as publicações pode ser minuciosamente levantado através da sua correspondência.

\section{Baudelaire}

As traduções que Baudelaire fez de Poe e a importância delas não só para a descoberta de Poe na Europa, como mais tarde, numa via de retorno, para a valorização inicial de Poe nos Estados Unidos, são tema crítico comum desde que elas começaram a aparecer no cenário francês. $\mathrm{O}$ autor de Baltimore precisou de muitos 
anos após sua morte e da evidência de que os europeus, principalmente os franceses ${ }^{3}$, o valorizavam para que a academia americana lhe desse algum ouvido (o que acontece, na verdade, só nas primeiras décadas do século XX). E Baudelaire teve de fato grande responsabilidade por isso, ou ao menos procurou ter. Em carta a SainteBeuve ele afirma: Il faut, c'est-à-dire je désire, qu'Edgar Poe, qui n'est pas grandchose en Amérique, devienne un grand homme pour la France. ${ }^{4}$

O primeiro contato de Baudelaire com a obra de Poe foi provavelmente em 1847, a partir das traduções de alguns poucos contos feitas por Isabelle Meunier, inglesa casada com um francês que escrevia e traduzia para o jornal La démocratie pacifique (de linha definida pelo socialismo utópico de Fourier). Desde esse momento, como revelaria mais tarde em correspondência a Charles Asselineau ${ }^{5}$, ele foi definitivamente influenciado pelo estilo do autor e passou, ele próprio, a buscar e traduzir sua obra.

Esse entusiasmo se transformou em inúmeros contos publicados em diversos periódicos e nos volumes Histoires extraordinaires ${ }^{6}$, Nouvelles histoires extraordinaires e Histoires grotesques et sérieuses, dando corpo a um trabalho de tradução que durou de 1848 a 1865, cerca de dezessete anos ${ }^{7}$. Ainda hoje as traduções de Poe feitas por Baudelaire são as mais importantes da língua francesa, apesar de muitas observações sobre detalhes, feitas nos últimos anos, as terem relativizado. ${ }^{8}$

\footnotetext{
${ }^{3}$ Outros países europeus, e a Espanha é um bom exemplo, começaram a publicar contos de Poe depois das traduções de Baudelaire. Muitas dessas traduções eram publicadas em periódicos e frequentemente não apresentavam autoria ou eram, simplesmente, apresentadas como sendo de autoria de escritores ou pretensos escritores - locais.

4 "É preciso, quer dizer, eu desejo, que Edgar Poe, que não é grande coisa na América, se torne um grande homem para a França." Carta a Sainte-Beuve, de 19 de março de 1856. Correspondance. Paris : Gallimard, 1993. vol. II, p. 343. Apud HENNEQUET, Claire. "Baudelaire traducteur de Poe". Disponível em: http://baudelaire-traducteur-de-poe.blogspot.com. Acessado em 26/07/2010.

${ }^{5}$ Escritor e crítico de arte (1820-1874), Asselineau era amigo de Baudelaire e foi seu primeiro biógrafo (Charles Baudelaire, sa vie et son oeuvre). Após a morte de Baudelaire foi responsável, juntamente com Théodore de Banville, pela organização da $3^{\mathrm{a}}$ edição de Les fleurs du mal.

${ }^{6}$ Não podemos deixar de comentar aqui que o título Histoires extraordinaires foi criado por Baudelaire para reunir os contos que havia traduzido desde a primeira publicação. Esse título é hoje um dos títulos preferenciais para antologias de contos de Poe em várias línguas, revelando um caso típico de influência do trabalho do tradutor na trajetória de uma obra.

7 É importante destacar também o aspecto financeiro desse trabalho: essas traduções também representaram para Baudelaire, durante vários anos, meios necessários para suprir algumas de suas necessidades.

${ }^{8}$ Além disso, não se pode esquecer que muito da imagem de um Poe perdido entre suas misérias psicológico-financeiras e o ópio (notícias biográficas algo fantasiosas a que Baudelaire teve acesso), foi reproduzido pelo poeta francês. A crítica não se cansa de comentar a identificação de ordem pessoal que Baudelaire descobriu ao aproximar-se de Poe: engendrava-se aí a "marginalidade" poética do século XIX.
} 
Com esse trabalho Baudelaire teve seu nome e sua obra para sempre ligados a Poe, mas incomodou-se bastante com isso. É verdade que ele sempre admitiu a identificação e em sua correspondência há declarações como essa: La première fois que j'ai ouvert un livre de lui, j'ai vu, avec épouvante et ravissement, non seulement des sujets rêvés par moi, mais des PHRASES pensées par moi, et écrites par lui vingt ans auparavant. ${ }^{9}$ Sua própria obra, no entanto, acabou mais tarde sendo vista por alguns como uma emulação da obra do autor americano, o que, para alguém com uma tendência patológica a sentir-se injustiçado, foi psicologicamente desastroso: on m'accuse, moi, d'imiter Edgar Poe! Savez-vous pourquoi j'ai si patiemment traduit Edgar Poe? Parce qu'il me ressemblait.... . ${ }^{10}$

O que a correspondência — mesmo entre amigos — nos revela é portanto uma atitude bastante segura da parte de Baudelaire em relação à obra de Poe, ainda que possa ser considerada algo narcísica, como já foi levantado pela crítica ${ }^{11}$. É verdade que quando Baudelaire "encontra" Poe ele já tem boa parte da sua principal obra, Les fleurs $d u$ mal, bastante adiantada, mas ele termina essa obra e escreve Petits poèmes en prose enquanto traduz os contos de Poe. De qualquer modo, a correspondência pessoal do poeta francês nos informa que a leitura e o extenso trabalho de tradução foram um "complemento", uma feliz aproximação de obras gêmeas.

É evidente que essa relação já gerou belos estudos de caso: descobrir como uma influência, vertida e localizável em um trabalho de tradução, poder ser estudada na obra original de um autor. Nenhum crítico encontrou fundamentos para apontar influência excessivamente explícita na obra de Baudelaire, mas essa obra é tão significativamente diferente da de seus contemporâneos franceses, e Baudelaire foi tão devotado à obra de Poe, que não há como se desconsiderar a importância dessa ascendência. Paul Valéry, por exemplo, atribui a Poe a guinada de Baudelaire em sua obra, afirmando que o autor de Les fleurs du mal teria sido um belo candidato a parnasiano caso não tivesse conhecido a obra do autor americano - Valéry, no entanto, não vê nesse processo um problema, mas um caso do que ele chamou de "troca de valores":

\footnotetext{
9 "Na primeira vez que abri um livro dele vi, com susto e deleite, não somente os assuntos sonhados por mim, mas FRASES pensadas por mim e escritas por ele vinte anos antes." Carta de Charles Baudelaire a Théophile Thoré, junho de 1864. Correspondance.II. P.386. Apud: idem, ibidem.

10 "... acusam-me, a mim, de imitar Edgar Poe! Sabes por que traduzi tão pacientemente Edgar Poe? Porque ele se parecia comigo..." Apud: idem ibidem.

${ }^{11}$ Idem, ibidem.
} 
.... échangent des valeurs. Chacun d'eux donne à l'autre ce qu'il a; il en reçoit ce qu'il n'a pas. Celui-ci livre à celui-là tout un système de pensées neuves et profondes. Il l'éclaire, il le féconde, il détermine ses opinion sur une quantité de sujets: philosophie de la composition, théorie de l'artificiel, compréhension et condamnation du moderne, importance de l'exceptionnel et d'une certaine étrangeté, attitude aristocratique, mysticité, goût de l'élégance et de la précision, politique même... Tout Baudelaire en est imprégné, inspiré, approfondi.

Mais, en échange de ces biens, Baudelaire procure à la pensée de Poe une étendue infinie. Il la propose à l'avenir. Cette étendue qui change le poète en luimême, dans le grand vers de Mallarmé ["Tel qu'en Lui-même enfin l'éternité le change...], c'est l'acte, c'est la traduction, ce sont les préfaces de Baudelaire qui l'ouvrent et qui l'assurent à l'ombre du misérable Poe. ${ }^{12}$

Valéry, portanto, ciente de seu papel de discípulo direto de Mallarmé e indireto de Baudelaire, lê o Baudelaire-tradutor como uma das facetas do Baudelaireautor, e lê a presença de Poe na sua obra como um fato intimamente ligado à idéia de criação, influência, co-influência e divulgação, e não um caso de plágio ou imitação por parte do autor francês. Poderíamos falar então de uma típica "angústia da influência" em Les fleurs du mal, apenas refinada pela presença de um trabalho intenso de aproximação de um determinado autor, possibilitado pelo trabalho de tradução.

Mas há nesse processo um elemento interessante. Fala-se da influência de Poe nos poemas de Les fleurs du mal, mas o trabalho de tradutor de Baudelaire privilegiou especialmente a prosa, vertendo para o francês todos os contos a que teve acesso. Baudelaire ousou pouquíssimo entre os versos de Poe e eles acabaram sendo o projeto especial de tradução de outro escritor, Stéphane Mallarmé.

\section{Mallarmé}

Quando Verlaine resolveu elaborar o livro Poètes maudits, escolheu alguns poetas e escreveu sobre eles ${ }^{13}$, apresentando também poemas de cada um. Mallarmé,

\footnotetext{
12 "Baudelaire, Edgar Poe, trocam valores. Cada um deles dá ao outro o que tem, recebe o que não tem. Este último dá ao primeiro um sistema de pensamentos novos e profundos. Ele o esclarece, o fecunda, determina suas opiniões sobre muitos assuntos: filosofia da composição, teoria do artifício, compreensão e condenação do moderno, importância do excepcional e de uma certa estranheza, atitude aristocrática, misticismo, gosto pela elegância e pela precisão, mesmo política... Todo Baudelaire está impregnado disso. / Mas, em troca por esses bens, Baudelaire dá ao pensamento de Poe uma extensão infinita. Ele a propõe ao futuro. Esta extensão que transforma o poeta em si próprio, no grande verso de Mallarmé [Tal como em si próprio a eternidade o muda... in: "Tombeau pour Edgar Poe"], é o ato, é a tradução, são os prefácios de Baudelaire que o abrem e que o asseguram à sombra do miserável Poe. VALÉRY, Paul. Variations. Paris: Gallimard, 2005. V. 1, p. 243.

${ }^{13}$ Especificamente: Tristan Corbière, Arthur Rimbaud, Stéphane Mallarmé, Marceline DesbordesValmore, Villiers de l'Isle Adam e Pauvre Lelian, anagrama de Paul Verlaine.
} 
um dos escolhidos, recebeu de Verlaine o pedido de uma "mini-biografia" e respondeu no que acabou por se tornar uma de suas cartas mais importantes, por se tratar de uma pequena autobiografia. Nessa carta, de 16 de novembro de 1885, Mallarmé, que vivia como professor de inglês, afirma ter originalmente aprendido a língua para ler Edgar A. Poe.

Il n'y avait pas, vous le savez, pour un poëte à vivre de son art même en l'abaissant de plusieurs crans, quand je suis entré dans la vie; et je ne l'ai jamais regretté. Ayant appris l'anglais simplement pour mieux lire Poe, je suis parti à vingt ans en Angleterre, afin de fuir, principalement; mais aussi pour parler la langue, et l'enseigner dans un coin, tranquille et sans aurtre gagne-pain obligé: je m'étais marié et cela pressait. ${ }^{14}$

Mallarmé, confessadamente influenciado por Baudelaire, foi um grande leitor de Poe e, nesse momento, já passados 18 anos da morte de Baudelaire, era a principal "autoridade" sobre Poe na França. Algum tempo antes, em uma carta de 22 de março de 1881 para Édouard Rouveyre, editor, Mallarmé afirma:

J'ai repris les choses où, la mort l'interrompant lui-même, les a laissées Baudelaire, c'est-à-dire à la traduction de ces poèmes extraordinaires, que tout le monde a lus dans une revue ou un journal, de temps à autre; mais que je n'ai point publié encore dans leur ensemble. ${ }^{15}$

A crítica vai ver na relação de Mallarmé com a obra de Poe uma forma que o autor achou de escapar ao peso e à presença de Baudelaire na sua própria obra: um desvio apenas, na verdade, já que a referência de Poe chegava até ele também via Baudelaire. Victor Hugo e Baudelaire, ambos vivos quando Mallarmé começa a escrever, eram os grandes poetas do seu tempo, sendo que este último era o dono da poesia de fato "nova" que ele viria a "seguir". Edgar A. Poe, portanto, é consequentemente um autor pelo qual ele imediatamente vai se interessar.

E o primeiro dado explícito desse interesse vai aparecer na composição de um poema famoso de Mallarmé, "L'azur". Em uma carta, seguindo o texto de Poe

\footnotetext{
${ }^{14}$ Não havia como, o senhor o sabe, para um poeta, viver de sua arte mesmo a rebaixando muitos graus, quando entrei na vida; e jamais me arrependi disso. Tendo aprendido inglês simplesmente para melhor ler Poe, parti aos vinte anos para a Inglaterra, a fim de fugir, principalmente; mas também para falar a língua e ensiná-la em um canto, tranquilo e sem outro ganha-pão necessário: eu havia me casado e isso me apressava. Correspondance. V. II, p. 301. Desse ponto em diante a correspondência de Mallarmé será referida como $C M$.

15 "Retomei as coisas onde, a morte o tendo interrompido, Baudelaire as deixou, quer dizer, na tradução dos poemas extraordinários, que todo o mundo leu em uma revista ou jornal, vez por outra; mas que ainda não publiquei no seu conjunto." CM. V. II, p. 223-223.
} 
"Filosofia da composição", Mallarmé tenta "explicar" a escritura do poema a um amigo, descrevendo, verso a verso, intenções originais e o que ele deveria "provocar" no leitor, mimetizando o próprio texto de Poe na sua "explicação" sobre "O corvo". Trata-se da carta de Mallarmé, então com 21 anos, a Henri Cazalis, outro poeta seu amigo, datada de 7 de janeiro de 1864 :

(...) Henri; qu'il y a loin de ces théories de composition littéraire à la façon dont notre glorieus Emmanuel prend une poignée d'étoiles dans la voie lactée pour la semer sur le papier et les laisser se former au hasard en constellations imprévues! Et comme son âme enthousiaste, ivre d'inspiration, reculerait d'horreur, devant ma façon de travailler! Il est le poète lyrique dans tout son admirable épanchement. Toutefois, plus j'irai, plus je serai fidèle à ces sévères idées que m'a légueées mon grand maître Edgar Poe.

Le poème inouï du Corbeau a été ainsi fait. Et l'âme du lecteur jouit absolument comme le poète a voulu qu'elle jouit... Ainsi suis ma pensée dans mon poème et vois si c'est là ce que tu a senti en me lisant. Pour débuter d'une façon plus large, et approfondir l'ensemble, je ne parais pas dans la première strophe. L'azur torture l'impussant en général. Dans la seconde, on commence à se douter, par ma fuitedevant le ciel possesseur, que je souffre de cette cruelle maladie. Je prépare dans cette strophe encore, par une forfanterie blasphématoire, Et quelle nuit hagarde, l'idée étrange d'invoquer les brouillards. La prière au "cher ennuie" confirme mon impuissance. Dans la troisième strophe, je suis forcené comme l'homme qui voit réussir son voeu acharné. La quatrième commence par une exclamation grotesque d'écolier délivré: "Le ciel est mort!" Et tout suite, muni de cette admirable certitude, j'implore la Matière. Voilà bien la joie de l'Impuissant. Las du mal qui me ronge je veux goûter au bonheur commun de la foule, et attendre la mort obscure... Je dis "je veux". Mais l'ennemi est un spectre, le ciel mort revient, et je l'entends qui chante dans les cloches bleues. Il passe indolent et vainqueur, sans se salir à cette brume et me transperce simplement. A quoi je m'écrie, plein d'orgueil et ne voyant pas là un juste châtiment à ma lâcheté, que j'ai une immense agonie. Je veux fuir encore, mais je sens mon tort et avoue que je suis hanté. Il fallait toute cette poignante révélation pour motiver le cri sincère et bizarre de la fin, $l^{\prime}$ "azur"... Tu le voie pour ceux qui, comme Emmanuel et comme toi, cherchent dans un poème autre chose que la musique des vers, il y a là un vrai drame. Et ç'a été une terrible difficulté de combiner, dans une juste harmonie, l'élément dramatique hostile à l'idée de poésie pure et subjective avec la sérénité et le calme de lignes nécessaires à la Beauté.

Mais tu va me dire que voilà beaucoup d'embarras pour des vers qui en sont bien peu dignes. Je le sais. Cela, toutefois, m'a accusé de t'indiquer comment je juge et conçois un poème. Abstraits de ces lignes toute allusion à moi, et tout ce qui a rapport à mes vers, et lis ces pages, froidement, comme l'ébauche fort mal écrite et informe d'un article d'art..

Tuus,

Stéphane Mallarmé $e^{16}$

\footnotetext{
16 "Henri, estamos longe destas teorias literárias de composição segundo as quais nosso glorioso Emmanuel toma um punhado de estrelas da via láctea para semeá-las sobre o papel e deixá-las formar ao acaso constelações imprevistas! E como sua alma entusiasta, ébria de inspiração, recuaria de horror frente a meu modo de trabalhar! Ele é o poeta lírico, em todo seu admirável derramamento. Entretanto, quanto mais adiante for, mais serei fiel às ideias severas que me legou meu grande mestre Edgar Poe. / O poema inaudito do Corvo foi feito assim. E a alma do leitor goza absolutamente como o poeta quis que ela gozasse. Ela não sente nenhuma impressão além daquelas que ele previu. - Assim, siga meu
} 
Essa carta mostra a importância, digamos, teórica, do pensamento de Poe para a obra de Mallarmé. É bastante interessante perceber o passo-a-passo do poeta "aprendendo" e explicando como fazer poemas, seguindo fielmente — e quase ingenuamente - o texto de referência. Algum tempo mais tarde, Mallarmé se aproximaria da obra de Poe realmente como tradutor e aí novamente o peso do trabalho de Baudelaire aparece: num movimento contrário ao de seu mestre, Mallarmé vai traduzir apenas a poesia de Poe. Os contos, como até muito recentemente para os franceses, permaneceram exclusividade baudelairiana.

Mas o autor obcecado pela forma em seus próprios poemas não transferiu esse mesmo interesse para o seu trabalho como tradutor. Os poemas de Poe são rimados e metrificados, e respondem a intenções claras de assunto, efeitos, musicalidade e ritmo. Mallarmé traduziu-os em prosa: estrofe a estrofe, os poemas de Poe foram vertidos em uma belíssima prosa poética, numa "versão" onde, portanto, parte do trabalho de Poe é recuperada, mantida, graças, talvez muito mais, ao próprio trabalho de Mallarmé como poeta, antes do que a sua perícia como tradutor.

Impossível não se solidarizar com o autor: verter para uma língua românica a concisão sintática e a multiplicidade vocabular da língua inglesa, resguardando estritos padrões formais poéticos é reconhecidamente um trabalho bastante difícil. O que percebemos, na leitura das traduções de Mallarmé, é que Poe o impressionava sobremaneira semanticamente, o que faz com ele se esforce para manter, quase

pensamento em meu poema, e veja se é isso que sentiste lendo-me. Para começar de um modo mais amplo, e aprofundar o conjunto, não apareço na primeira estrofe. O azur tortura o impotente em geral. $\mathrm{Na}$ segunda, começa-se a suspeitar, por minha fuga frente ao céu possuidor, que eu sofra dessa terrível doença. Preparo nesta estrofe ainda, por uma fanfarronice blasfematória Et quelle nuit hagarde, a ideia estranha de invocar as névoas. A oração ao Cher Ennui confirma minha impotência. Na terceira estrofe estou em fúria como o homem que vê vingar sua promessa enraivecida. A quarta começa com uma exclamação grotesca, de estudante libertado. Le ciel est mort! E, em seguida, munido dessa certeza admirável, imploro a Matéria. Aí está então a alegria do Impotente. Cansado do mal que me rói, quero experimentar a felicidade comum da massa e esperar pacientemente a morte obscura... Digo: Je veux! Mas o inimigo é um espectro, o céu morto volta, e eu o escuto cantar nos sinos azuis. Ele passa, indolente e vencedor, sem sujar-se nessa bruma e simplesmente me transpassa. Ao que clamo, cheio de orgulho e não enxergando aí um castigo justo para minha prostração, que sinto uma imensa agonia. Ainda quero fugir, mas percebo meu erro e reconheço que estou assombrado. Era necessária toda essa penosa revelação para motivar o grito sincero, e bizarro, do fim, o azur... - Vês, para aqueles que, como Emmanuel e como tu, procuram em um poema outra coisa além da música do verso, há aí um verdadeiro drama. E foi uma dificuldade terrível combinar, em justa harmonia, o elemento dramático, hostil à ideia de Poesia pura e subjetiva, com a serenidade e a calma de linhas necessárias à Beleza. / Mas vais me dizer que é muita enrolação para uns versos que são bem pouco dignos disso. Eu o sei. Entretanto, me agradou te contar como eu julgo e concebo um poema. Abstrai dessas linhas toda alusão a mim, e tudo que tem relação com meus versos, e lê essas quatro páginas friamente, como o esboço, muito mal escrito e informe, de um artigo sobre arte. / Tuus, / Stéphane Mallarmé" CM. V. 1, pp. 103105. 
completamente, a "ideia" do verso, e não sua forma, em detrimento, inclusive, da sua própria identidade como poeta, cuja sofisticação formal se faz presente desde os poemas da juventude.

E há ainda outra questão a ser considerada. Numa reação ao que havia sido a postura tradutória francesa durante o século anterior, a França do século XIX passou a defender a tradução paciente, fiel, "exata". Conselhos para o trabalho pedagógico de ensino de línguas descartam o conceito de version e incluem a ideia de calque, uma tradução onde a "fidelidade" ao original deve ser o principal valor a ser considerado ${ }^{17}$. No mundo propriamente literário, Gérard de Nerval, por exemplo, introduzindo uma antologia traduzida de poemas alemães afirma que o seu trabalho era ali "exato":

Pour moi, j'offre ici des traductions de vif enthousiasme et de premier jet, que je n'ai peut-être pas réussi à faire bonnes, mais qui du moins sont exactes et consciencieuses. Les jugements n'avancent rien en littérature; des traductions fidèles peuvent, je crois, davantage. Quant aux imitations, on n'en veut plus, et on a raison. ${ }^{18}$

Mas, para Mallarmé, essa nova disposição aparentemente não é uma preocupação. Mallarmé traduz como poeta, o que significa em alguns momentos, no seu caso específico, algo muito mais próximo de uma versão adaptada, especialmente, como afirmado, do ponto de vista da apresentação formal dos poemas. ${ }^{19}$

1871 é o ano do fim do "exílio". De 1863 a 1871, Mallarmé peregrinou por cidades pequenas do interior da França, cumprindo seus encargos de professor em liceus de que não gostava e onde igualmente não era muito bem quisto: "poetas" eram demasiadamente assustadores para aquela conservadora burguesia. E para cúmulo de desconforto, seu salário era muito baixo e mal permitia que sustentasse a si próprio, sua mulher e sua filha. Mas em 1871 alguns amigos começam uma campanha para conseguir trazê-lo para Paris, aventando inclusive cargos em escritórios de editoras

\footnotetext{
${ }^{17}$ Ver, sobre o assunto: HOOF, Henri van. Histoire de la traduction en occident: France, GrandeBretagne, Allemagne. Paris: Éditions Duculot, 1991; HULST, Lieven d'. Cent ans de théorie française de la traduction: de Batteux à Littré (1748-1847). Lille: Du Septentrion, 1990.

18 "Quanto a mim, ofereço aqui traduções de grande entusiasmo e diretas, que talvez não tenha conseguido fazer boas, mas que ao menos são exatas e conscienciosas. Os julgamentos não adiantam nada em literatura: acredito que traduções fiéis podem mais. Quanto às imitações, não as queremos mais, e temos razão." Trecho da "Introdução" à: Poésies allemandes: Klopstock, Goëthe, Schiller, Burger: morceaux choisis et traduit par M. Gerard. Paris, Bureau de la Bibliothèque Choisie, 1830. http://gallica.bnf.fr/ark:/12148/bpt6k74764j.image.r=po\%C3\%A9sies+allemandes.f6.pagination.langF R, acesso em 30/07/2010.

${ }^{19} \mathrm{O}$ "poema em prosa" começa a ser valorizado, depois de Aloysius Bertrand, por Baudelaire e pelo próprio Mallarmé.
} 
(Hachette), como tradutor de inglês e mesmo correspondente em Londres, ou empregos no comércio. Como Mallarmé era professor de inglês, e o conhecimento de outras línguas não era algo comum, seus amigos supunham poder fazer proveito disso para procurar um emprego especial para ele. Em meio a consultas recíprocas, um algo exigente Mallarmé - para quem aparentemente não tinha assim tanto para oferecer — ainda em Avignon, responde, em $1^{\circ}$ de março de 1871, a uma carta de Catulle Mendès, outro poeta importante do período, sobre suas possibilidades de trabalho:

Je ne connais de l'anglais que les mots employés dans le volume des poésies de Poe, et je les prononce, certes, bien - pour ne pas manquer au vers.

Je puis, le dictionnaire et la divination aidant, faire un bon traducteur, surtout de poètes, ce qui est rare. Mais je ne crois pas que cela constitue une place dans la maison Hachette, à moins d'un arrangement par lequel je livrerais, à un prix indulgent, un volume, je suppose, par année. En un mot, croyez-vous que cette entreprise, dont je vous parlais récemment (et qui est une sorte de petit monument) pourrait suffire à la bienveillance que m'accorde la maison Hachette?

[...] J'ai peur, par instants, que l'occupation d'une maison de commerce, qui doit n'employer que des personnes d'une présence effective, et très réalisable, soit moins favorable même que le bureau (m'étais-je trompé?) entrevu à la faveur de votre dernière lettre, à des projets certains qui, en somme, forment ce que vous attendez de moi.

[...] Toutefois, comme après tout on n'a pas d'excuse, à mon âge, de travailler difficilement, [...]. Il faudrait donc, puisque c'est l'anglais qui est en jeu, accepter d'abord la place de Londres, qui me permettra de le rapprendre - sauf à revenir vers cet hiver à Paris.

Qui sait, cependent, si deux ou trois correspondances, de journaux ne me permettraient pas là-bas d'atteindre le même but, d'une façon qui concorderait peutêtre mieux avec l'avenir?

[...] Maintenant, cher ami, votre main, afin que je ne croie pas que je me parle à moi-même en tout ceci, tant nous nous confondons aisément.

[...] Amitiés à Madame Judith,

Stéphane Mallarmé2

\footnotetext{
20 "Só conheço do inglês as palavras usadas no volume de poemas de Poe, e as pronuncio, certamente, bem - para não estragar o verso. / Posso, dicionário e adivinhação ajudando, ser um bom tradutor, sobretudo de poetas, o que é raro. Mas não acredito que isso constitua um posto na maison Hachette, a não ser em um arranjo no qual eu entregaria, a um preço indulgente, um volume, suponho, por ano. Em uma palavra, o senhor acredita que esta empreitada, de que lhe falei recentemente (e que é um tipo de pequeno monumento) poderia ser suficiente para a boa vontade que me concede a maison Hachette? / [...] Tenho medo, às vezes, que a ocupação de uma casa de comércio, que deve empregar apenas pessoas com uma presença efetiva, e muito ativa, seja até menos favorável que o escritório (enganavame?) entrevisto no favor de sua última carta, com projetos certos que, ainda por cima, formam o que vocês esperam de mim/formam o que espera de mim. / [..] De qualquer modo, como depois de tudo não há desculpa, na minha idade, para não trabalhar laboriosamente [...] Seria necessário, portanto, já que é o inglês que está em jogo, aceitar de início o lugar em Londres, que me permitirá reaprendê-lo resguardando a possibilidade de vir em torno deste inverno para Paris. / Quem sabe, entretanto, se duas ou três correspondências de jornais não me permitiriam lá atingir o mesmo objetivo, de maneira mais coerente com o futuro? / [...] Agora, caro amigo, sua mão, a fim de que eu não acredite que falo só para mim mesmo em tudo isso, tanto nós nos confundimos facilmente. / [...]Amizades à Madame Judith. / Stéphane Mallarmé" CM. V. I, pp. 339-340.
} 
Para o nosso interesse aqui, o que esse trecho explicita é a relação de Mallarmé com a língua inglesa e como ele poderia estar prestes a transpor a barreira entre o trabalho de tradução feito por escolha própria e o eventual trabalho contratado. O detalhe principal talvez seja o fato de que ele se sentia à vontade para traduzir poesia em língua inglesa, mas não para trabalhar com essa língua em outros ambientes ou para suprir outros tipos de necessidades. É interessante considerar a distinção nítida, para Mallarmé, entre esses trabalhos possíveis, e como efetivamente sua intimidade maior com a linguagem poética em sua própria língua definia a sua "intimidade" com a língua estrangeira.

Ao fim e ao cabo, nenhuma dessas propostas "comerciais" será efetivada. Finalmente, em 1871, Mallarmé muda-se para Paris onde continuará a trabalhar como professor em mais de um liceu, mas a partir daí outros projetos surgirão: revistas, alguns textos para jornais, vários para revistas e suas traduções.

Em 1873 Mallarmé conhece Édouard Manet, começando uma amizade sólida que durará até a morte deste, em 1883. Juntos eles publicaram uma das edições mais valiosas do século XIX francês: um poema de Poe, "The Raven", traduzido por Mallarmé e ilustrado por Manet: Le Corbeau (The raven), poème par Edgar Poe. In folio, 7 páginas e 6 desenhos.

Essa edição foi feita por Richard Lesclides, e saiu no dia 2 de junho de 1875, mas só depois do que Mallarmé chamou de o affaire Lemerre. O editor Alphonse Lemerre, já há algum tempo, havia se comprometido a publicá-lo, mas começou a hesitar no início daquele ano. A correspondência do editor, guardada por Mallarmé, atesta a mudança de opinião de Lemerre: entre 11 e 15 de março o editor vai de duvidoso a agressivo. Em carta do dia 11, Lemerre afirma que, segundo alguns professores consultados, a publicação desse volume será bastante imprópria para a coleção de livros em que se apoia a editora. No dia 13, já mais seguro da rejeição: "Sua tradução que eu não havia lido, é absolutamente obscura e não pode ser publicada por esse seu criado." Finalmente, no dia 15, ele recusa o trabalho: "O poema oferece tais insanidades que é impossível, para uma casa séria, publicá-lo." ${ }^{21}$

A reputação de obscuro já chegava aos leitores de Mallarmé, corrompendo previamente suas leituras: a crítica hoje é unânime em afirmar que não há nada de obscuro ou difícil na sua versão. Esse acontecimento, avalia-se, teria tido efeito

\footnotetext{
${ }^{21}$ CM. V. II, p. 59-60.
} 
também sobre o Affaire du Parnasse (o mesmo Lemerre é quem publicava a revista do Parnaso), no ano seguinte, em que Mallarmé, após ter sido publicado no primeiro e no segundo volumes, tem poemas rejeitados para o terceiro volume sob o argumento de "obscuridade" e de que seriam "motivos de riso", nos termos supostamente expressados por Anatole France, um dos organizadores daquele volume. Na verdade, a fama de obscuro perseguirá Mallarmé por várias décadas, mesmo após sua morte. A melhor das suas respostas a isso é o texto "Mystère dans les lettres", veiculado em um volume de 1896 na Revue Blanche, em reação ao texto "Contre l'obscurité", de um jovem e ainda não famoso Marcel Proust.

Obscuro ou não, graças a essa tradução de "The raven" Mallarmé consegue uma repercussão considerável e mais olhares se voltam para o seu trabalho. O poeta inglês Swinburne é um dos que o descobrem dessa maneira e logo o coloca, em 1876, em contato com Mrs. Sara Sigourney Rice, a americana responsável pela organização do evento de homenagem a Poe, em Baltimore.

Esse evento foi bastante importante para a trajetória da obra de Poe, renegada pela sociedade americana, funcionando como o início de um desagravo. Inaugurou-se um novo túmulo e mais tarde foi editado um volume de homenagem no qual figurou um poema de Mallarmé, solicitado por Mrs. Rice, "Le tombeau de Edgar Poe", que se transformou em um dos poemas antológicos do autor: lá está um de seus versos mais famosos, "Dar um sentido mais puro às palavras da tribo"...

Le Tombeau d'Edgar Poe 22

Tel qu'en Lui-même enfin l'éternité le change,

Le Poëte suscite avec un glaive nu

Son siècle épouvanté de n'avoir pas connu

Que la mort triomphait dans cette voix étrange!

Eux, comme un vil sursaut d'hydre oyant jadis l'ange

Donner un sens plus pur aux mots de la tribu

Proclamèrent très haut le sortilège bu

Dans le flot sans honneur de quelque noir mélange.

Du sol et de la nue hostiles, ô grief!

Si notre idée avec ne sculpte en bas-relief

Dont la tombe de Poe éblouissante s'orne,

Calme bloc ici-bas chu d'un désastre obscur

Que ce granit du moins montre à jamais sa borne

Aux noirs vols du Blasphème épars dans le futur. ${ }^{23}$

${ }^{22}$ MALLARMÉ, S. Oeuvre complète. Paris: Gallimard, 2003. V. 1, p. 38. 
Algum tempo depois, mantendo, em francês, uma correspondência com a exnoiva de Poe, Sarah Helen Whitman, Mallarmé recebe dela o pedido de que "explique" melhor o poema, pois afirmava que "seu francês" não parecia suficiente para compreendê-lo. Mallarmé realiza então o sonho de seus futuros exegetas: a tradução de seu próprio texto ${ }^{24}$.

É, na verdade, apenas uma gentileza que ele procura fazer, sem nenhuma pretensão realmente poética. Aliás, considerando a carta para Catulle Mendès em que ele afirmava ser um bom tradutor de poesia, para o francês, percebemos que de fato isso não parecia se estender na direção contrária. E ele tinha consciência disso, ao afirmar, na carta de 31 de julho de 1877: “je joins à cette lettre une traduction probablement barbare que j'ai faite mot à mot de ses quatorze vers" ${ }^{25}$ Além da tradução, Mallarmé ainda acrescenta sete notas "explicativas", tentando glosar, também em inglês, o que provavelmente considerava que sua própria tradução não havia conseguido dizer ${ }^{26}$.

Such as into himself at last Eternity changes him,

The poet arouses with a naked hymn ${ }^{27}$

His century overawed not to have known

That death extolled itself in this ${ }^{28}$ strange voice:

But, in a vile writhing of an hydra, (they) once hearing the Angel ${ }^{29}$

To give $e^{30}$ too pure a meaning to the words of the tribe,

They (between themselves) thought (by him) the spell drunk

In the honourless flood of some dark mixture ${ }^{31}$

Of the soil and the ether (which are) enemies, O Struggle!

If with it my idea does not carve a bas relief

Of which Poe's dazzling ${ }^{32}$ tomb be adorned,

\footnotetext{
${ }^{23} \mathrm{Na}$ tradução de Augusto de Campos: "A tumba de Edgar Poe/ Tal que a Si-mesmo enfim a Eternidade o guia, / O Poeta suscita com o gládio erguido/ Seu século espantado por não ter sabido/ Que nessa estranha voz a morte se insurgia!/ Vil sobressalto de hidra ante o anjo que urgia/ Um sentido mais puro às palavras da tribo,/ Proclamaram bem alto o sortilégio atribu-/Ído à onda sem honra de uma negra orgia./ Do solo e céu hostis, ó mágoa! Se o que escrevo/ — Ideia e dor — não esculpir baixo-relevo/ Que ao túmulo de Poe luminescente indique,/ Calmo bloco caído de um desastre obscuro,/ Que este granito ao menos seja eterno dique/ Aos vôos da Blasfêmia esparsos no futuro." in: $O$ anticrítico. São Paulo: Companhia das Letras, 1986. p. 157.

${ }^{24}$ Alguns críticos já consideraram esse um dos principais documentos sobre a obra de Mallarmé.

25 "acrescento a esta carta uma tradução provavelmente bárbara que fiz, palavra por palavra, de seus quatorze versos". CM. V. II, p. 154-156.

${ }^{26} \mathrm{CM}$, II, p. 155 .

${ }^{27}$ Naked hymn means when the words take in death their absolute value. [Essa e as próximas seis notas são do próprio autor.]

${ }^{28}$ This: his own.

${ }^{29}$ The Angel: the above said Poet.

${ }^{30}$ To give: giving.

${ }^{31}$ _ : in plain prose — charged him with always being drunk.
} 
(A) Stern block here fallen from a mysterious disaster,

Let this granite at least show forever their bound

To the old flights of Blasphemy (still) spread in the future ${ }^{33}$.

Mrs. Whitman compreendeu o poema e nós ganhamos uma espécie de "autocomentário" de Mallarmé ${ }^{34}$. A glosa que ele produz é particularmente curiosa: a principal preocupação é claramente semântica, o que contradiz a postura mais radical que Mallarmé sempre manteve na construção de seus poemas. É claro que ele aqui responde cortesmente ao pedido de Mrs. Whitman, mas não deixa de ser interessante perceber como, quando ele tem que "abolir" as ambiguidades que sua sintaxe original consegue, o texto ainda assim não perde suas imagens e ideias mais fortes. Não se pode aqui deixar de supor alguma limitação na língua alvo, mas ela parece inclusive trabalhar a seu favor, mantendo muito da estranheza que Mallarmé constantemente buscava em sua própria língua. A ausência de rimas ou métrica na versão em inglês, ainda que com a manutenção da divisão entre os versos, também é uma forma aproximada da tradução que o próprio Mallarmé fez do conjunto dos poemas de Poe.

Em 1888, após um longo périplo de dificuldades editoriais, registrado às vezes dolorosamente nas suas cartas, Mallarmé publicou Les poèmes d'Edgar Poe. Novamente com "Le corbeau" e as ilustrações de Manet, mas somando um total de 21 poemas e 16 Romances et vers d'album - poemas e pequenas narrativas poéticas além de uma respeitosa dedicatória a Baudelaire, o "Tombeau d'Edgar Poe" e, ao final, comentários a cada um dos poemas e alguns dos "romances". As traduções, todas, em bela prosa poética, com parágrafos substituindo estrofes e alguns ritmos e rimas internas.

Essas traduções nos mostram, além de uma precisão formal final, uma intimidade muito grande por parte do tradutor com o autor, seja pelos mais de vinte anos de leitura e trabalho sobre a obra, seja por uma identificação pessoal com ela, a ponto de encontrarmos comentário, como em uma carta de maio de 1886, a John Ingram, editor e biógrafo de Poe na Inglaterra, em que se sente seguro para atestar,

\footnotetext{
${ }^{32}$ Dazzling: with the idea of such a bas relief.

${ }^{33}$ Blasphemy: against Poets, such as the charge of Poe being drunk.

${ }^{34}$ De qualquer modo, outras duas traduções ainda foram feitas — uma pela própria Mrs. Whitman e enviadas ao próprio Mallarmé, que as agregou ao volume Les poèmes d'Edgar Poe, em que Mallarmé reuniu sua tradução dos poemas do autor americano.
} 
acertadamente, como sendo um pastiche um poema que lhe tinha sido enviado, publicado em um jornal americano e atribuído a Poe. ${ }^{35}$

No contexto geral da correspondência de Mallarmé, suas traduções de Poe ocupam um espaço significativo. A constância e a extensão temporal desse assunto nas cartas revelam a influência e a importância do autor americano no contexto poético francês e a ênfase sobre sua tradução. Os desafios editoriais são, no entanto, o comentário mais frequente, mas é a persistência de Mallarmé e o fato de que ele realmente acreditava na obra de Poe e em suas próprias traduções que mantém o interesse inicialmente promovido por Baudelaire e fazem de Poe, ao longo das quase três décadas de trabalho de Mallarmé, um nome sólido no disputado - e algo territorialista - mundo literário francês. Envolvimentos e trocas com outros autores, com os promotores de Poe nos Estados Unidos, e mesmo com o pintor Manet na publicação de "Le corbeau", são também prova dessa relevância. E é, basicamente, a correspondência de Mallarmé que atesta toda essa trajetória.

\section{Referências bibliográficas}

MALLARMÉ, Stéphane. Correspondance: I à XI. Paris: Gallimard, 1959-1985. 12 tomos.

Correspondance: Lettres sur la poésie. Paris: Folio/Gallimard, 1995. Oeuvres complètes. Paris: Gallimard, 2003. 2 vol.

BAUDELAIRE, Charles. Oeuvres complètes. Paris: Robert Laffont, 1980.

CHARTIER, Roger (org.) La correspondance: les usages de la lettre au XIX siècle. Paris: Fayard: 1991.

DIAZ, Brigitte. L'épistolaire, ou la pensée nomade. Pais: Presses Universitaires de France, 2002.

LEDGER, Sally; LUCKHURST. The fin-de-siècle: a reader in cultural history c. 1880-1900. Oxford: Oxford University Press, 2000.

LLOYD, Rosemary. Mallarmé: the poet and his circle. Ithaca e Londres: Cornell University Press, 1999.

SMITH, Richard C. Mallarmé's children: symbolism and the renewal of experience. Berkeley/Los Angeles/Londres: University of California Press, 1999.

\footnotetext{
${ }^{35} \mathrm{CM}$, III, p. 34.
} 
VALÉRY, Paul. Variations. Paris: Gallimard, 2005. 